\title{
Measuring Family-centered Care in Intensive Care Units: Developing and Testing Psychometric Properties
}

\author{
Hasanali Jafarpoor ${ }^{1}$, Parvaneh Vasli ${ }^{1, *}$, Houman Manoochehri ${ }^{1}$, Farid Zayeri ${ }^{2}$
}

${ }^{1}$ School of Nursing and Midwifery, Shahid Beheshti University of Medical Sciences, Tehran, Iran

${ }^{2}$ Proteomics Research Center and Department of Biostatistics, School of Allied Medical Sciences, Shahid Behesht University of Medical Sciences, Tehran, Iran

\section{*Correspondence} p-vasli@sbmu.ac.ir (Parvaneh Vasli)

\begin{abstract}
Background: The availability of a valid scale to measure family-centered care (FCC) in intensive care units (ICUs) is of utmost importance. Purpose: the present study aimed to develop and test the psychometric properties of a new tool for measuring FCC in ICUs from the perspectives of patients' family members. Method: This methodological study was conducted from May 2018 to November 2019 at two Iranian universities of medical sciences. The scale items were thus designed based on the integration of the findings of a qualitative study and the results of a literature review. Then, face validity and content validity of the given scale were assessed. A total number of 204 and 203 family members of patients admitted to ICUs were recruited through convenience sampling method to examine construct validity via exploratory factor analysis and confirmatory factor analysis. The data were also analyzed using the IBM SPSS Statistics (Version 25) and AMOS software. The reliability of this scale was ultimately tested using Cronbach's alpha and test-retest correlation. Results: In the initial design, a 35-item scale was obtained. As face validity and content validity were determined, the number of items reduced to 26 cases. Following exploratory factor analysis, a 20 item scale containing 5 components (factors) including dignity, receiving information, support, family empowerment, and access to the physician, accounting for $63.4 \%$ of the total variance of the scale was developed. The reliability of this research tool was found acceptable based on Cronbach's alpha and intraclass correlation coefficient by 0.89 and 0.93; respectively. Conclusions/Implications for Practice: This study concluded with the development of a new scale for measuring FCC in ICUs entitled "FCCS-ICU". Accordingly, administrators and nurses are suggested to practice it to measure the extent and the manner of FCC implementation in ICUs from the perspectives of patients' family members.
\end{abstract}

\section{Keywords}

Family-centered care, Psychometric properties, Measurement, Intensive care unit

\section{Introduction}

Patient/Family-centered care is an approach for planning, provision, and evaluation of healthcare services, underlining partnerships between healthcare professionals, patients, and family members at all stages of care and across healthcare centers [1]. Family-centered care (FCC) is a method of care provision guaranteed by respectful involvement of family members and healthcare practitioners as well as consideration of patient/family health and well-being [2]. The key elements of FCC also include: (a) paying respect in the form of welcoming family, allowing family presence at the bedside, and giving them the right to ask questions about patients' health status, (b) sharing updated information with family members, (c) providing support as meeting patient/family needs and (d) facilitating involvement and empowerment of families through a partnership between family members and healthcare providers as well as inviting them to participate in care delivery and decision-making[3].

FCC is a practical method to provide high-quality services [2]. It can thus increase patient satisfaction, reduce hospitalization, moderate medical errors, improve safety, enhance employee satisfaction, enrich experiences of patients and their families regarding healthcare services, mitigate stress, develop communications, and consequently minimize conflicts [2, 4].

Intensive care units (ICUs) are special departments in hospitals providing healthcare services to critically ill patients [5]. For some reason, FCC is taken into account as a significant and necessary approach practiced in ICUs. Firstly, patients' critical conditions, ICU environment, and the long process of recovery can result in fear and unique challenges for patients and their family members [6]. As well, raising family awareness on how to provide care lowers the probability of admission of patients to ICUs [7]. Also, family members of ICU patients would 
like to stay at the bedside for more support and protection [8]. Another reason for the importance of FCC in ICUs is the critical conditions of patients and their inability to get information or to participate in decision-making. So, the active roles of patients' families and relatives as their representatives become more evident [9]. Accordingly, FCC has been defined as an objective for caregivers of critically ill patients and it is also a responsibility assigned to all administrators and clinicians in ICUs [10]. Many individual studies show the importance of family-centered care in non-Western societies [11-15].

FCC cannot be implemented simply, provided that it is measured and better understood [3]. So, its measurement should reflect an extensive range of objectives and elements that are vital to families [2]. It should be also performed using valid research tools revealing perspectives of families and healthcare providers [3]. Thus, the FCC needs to be measured concerning key principles and elements [2].

To the best of researchers' knowledge, few studies have thus far designed and tested the psychometric properties of a scale measuring FCC in pediatric settings, including two investigations by Shields and Tanner (2004) and Curley et al. (2013). [16, 17]. There have been also studying developing research instruments to measure FCC in ICUs. Mitchell et al. (2012) in their survey developed a scale entitled "FamilyCentered Care Survey-Adult Scale" based on the tool designed by Shields and Tanner (2004) to measure FCC in pediatric settings. In their report, they highlighted that the given research instrument had unacceptable validity for the measurement of FCC in ICUs [18]. On the other hand, Wang et al. (2016) in a study in Taiwan developed the same tool and examined its psychometric properties [3].

It should be noted that FCC as a care-centered approach can be influenced by sociocultural contexts and policies [19]. In this regard, Feeg et al. (2016) shed light on studies worldwide and found that family involvement and FCC implementation in different countries was poles apart due to some underlying reasons. [20]. Also, this care approach has been merely symbolized in the Western context, so it is necessary to implement it in other settings and nations [21]. However, according to the searches in the related literature, a valid scale measuring FCC in developing countries like Iran had not been developed. Therefore, this study aimed to design a new scale for measuring the FCC in ICUs.

\section{Method}

This methodological research was conducted using multiple stages as well as deductive and inductive approaches [22] to develop and test the psychometric properties of a new scale for measuring FCC in ICUs entitled "FCCS-ICU" from the perspectives of family members of ICU patients. This study was carried out from May 2018 to November 2019 in the ICUs of two hospitals affiliated to two universities in Iran in two phases, including item design and psychometric properties.

\subsection{Phase 1: Item Design}

Designing the items on the given scale included two stages i.e. a qualitative study and a literature review. In the qualitative study, 9 family members of ICU patients, 7 ICU nurses, 4 ICU anesthesiologists, as well as 4 nursing administrators including nursing supervisor, head nurse, and nurse manager (totally 24 individuals) were recruited for 24 semi-structured interviews and 7 nurses were also involved in a focus group discussion. After transcribing the interviews, they were analyzed using conventional content analysis.

After completing the qualitative study, a review of the related literature was performed to conclude and integrate the results of previous studies with the findings of the qualitative research and establishing the items of the given scale. So, articles addressing each of the following concepts were included: "FCC elements, FCC prerequisites, FCC consequences, family needs, family satisfaction in ICUs, tool, instrument, measurement, scale, and FCC questionnaire" through searches in the databases of Scientific Information Database (SID) and Magiran in Persian and PubMed, ISI Web of Knowledge, ProQuest, ScienceDirect, Scopus, and Google Scholar in English using the keywords below (in Persian and English) with no time limits: "family-centered care, family-oriented care, family involvement, family participation, caring partners, family needs, family satisfaction, family nursing, family-centered nursing, critical care, intensive care unit, ICU, measurement, inventory, tool, instrument, assessment, survey, psychometric properties".

As the articles were retrieved, their abstracts were examined and their full texts, in particular, their findings sections were reviewed in more detail and thoroughly if they were appropriate and accessible. At this stage, studies aimed at developing and testing psychometric properties of scales measuring FCC were further employed. The full report and results will be published as a separate study.

Designing the items was also based on deductive and inductive approaches. In this way, the findings of the qualitative study obtained initially based on a deductive approach were listed. Then, in the review of the selected articles, an analysis was performed according to the outputs of the qualitative study. At the same time, new elements or components (factors) of FCC if extracted from the selected articles using an inductive approach were recorded. The scale items were ultimately designed through integrating all the findings of the qualitative study and the literature review as well as collaboration and multi-stage examinations by all research team members.

\subsection{Phase 2: Psychometric Properties}

To test the psychometric properties of the FCCS-ICU, three stages were considered including (a) face validity and content validity, (b) construct validity using exploratory factor analysis (EFA) and confirmatory factor analysis (CFA), and (c) reliability as described below in detail.

\subsubsection{Face Validity and Content Validity}

\subsubsection{Face Validity}

After the initial development of the items and assessment of qualitative face validity, a total of 10 family members of 
patients admitted to ICUs were asked to examine the intelligibility and the clarity of the items in a face-to-face manner. At this stage, several revisions were also made through the replacement and relocation of some words in some items. To measure quantitative face validity, item impact was examined to determine the importance of each item and to remove the irrelevant ones [23]. Accordingly, a total number of 10 family members of ICU patients were requested to rate the importance of each of the items between 1 (not important at all) to 5 (very important). Then, item impact score was calculated through the multiplication of relative frequency considering the same percentage of people scoring the items by 4 and 5 by an important score, that is, the average score obtained for each item. Scores $\geq 1.5$ indicated the suitability of the item [23].

\subsubsection{Content Validity}

Content validity was met using qualitative and quantitative methods by a panel of experts consisting of 13 faculty members of different Schools of Nursing and Midwifery, specialized in ICU nursing as well as development and testing of psychometric properties of research instruments. In qualitative content analysis, the members of the panel of experts were also asked to discuss the items in terms of grammatical points and the use of correct and proper words [24]. Quantitative content validity was further examined by calculating the content validity ratio (CVR) and content validity index (CVI).

For CVR by which the necessity of each item could be examined, the panel of experts was requested to rate each item on a three-point Likert-type scale including "necessary" (score 3 ), "useful but not necessary" (score 2), and "not necessary" (score 1). Using the following formula, wherein $n_{e}$ shows the number of experts selecting "necessary" and $n$ indicates the total number of members of the panel of experts, CVR was calculated for each item and its value was compared with those in Lawshe's table. Accordingly, the minimum amount to be accepted for 13 experts was 0.54 [25].

$$
C V R=\frac{n_{e}-\frac{n}{2}}{\frac{n}{2}}
$$

Also, CVI was employed to examine inter-rater agreement regarding the relevance of the items to the scale in the form of item-level CVI (I-CVI) and scale-level CVI (S-CVI). To calculate I-CVI, the number of experts scoring items 3 or 4 in terms of relevance was divided by the total number of experts. In case that I-CVI for each item was $>0.79,0.7-0.79$, and $<$ 0.7 , they were considered as appropriate, in need of revision, and those to be removed [26]. Moreover, S-CVI was examined utilizing I-CVI of the items. The minimum amount to be accepted for S-CVI is 0.80 . To reduce the risk of a probability of chance in CVI, the modified Kappa statistic was used [27]. The amount to be accepted based on this statistic was $>8.0$ [28].

\subsubsection{Construct Validity}

\subsubsection{Exploratory factor analysis}

Given that the number of samples required for EFA is 3 to 10 per item [29], 8 participants for each item and a total of 208 family members of ICU patients (surgery, internal, heart, trauma, general) including parents, spouse, children, and siblings, playing the most significant roles in patient care and monitoring patient health status was recruited using a consecutive sampling method. The inclusion criteria were hospitalization of ICU patients for at least five days, patients and family members aged over 18 years, ability to speak and understand Persian, and active participation in patient care and follow-up of patient health conditions. A 4-item demographic questionnaire about family members including gender, marital status, level of education, and kinship and two items comprising leading cause of hospitalization and length of stay were also used. To improve the participants' accuracy in the completion of the items, the questionnaires were given to family members to fill out when patients had been transferred from ICUs to post-ICUs and there was less stress.

EFA was fulfilled using principal component analysis with varimax rotation and eigenvalue $>1$ to identify and reduce the components (factors) constituting the scale via the IBM SPSS Statistics software (Version 25). The suitability of the items and the sample adequacy for EFA were also respectively examined using Bartlett's test of sphericity and Kaiser-MeyerOlkin (KMO) test at the $<0.05$ significance level. The acceptable value for the KMO test was $>0.8$ (Munro et al., 2013). Items with commonalities $<0.50$ were ultimately removed [30].

\subsubsection{Confirmatory factor analysis}

Following EFA, CFA was performed to ensure the construct validity of the FCCS-ICU. At this stage, at least 10 individuals and a total of 203 family members of patients admitted to ICUs for each item were included based on convenience sampling method and following the inclusion criteria for the participants in EFA. To establish the difference in the participants in EFA and CFA, the Chi-square test was employed. For CFA, AMOS software and structural equation modeling (SEM) was further used. The acceptable indices and values for fitness of the model were Chi-square/degree-of-freedom ratio (CMIN/DF) $>3$, root mean square error of approximation (RMSEA) < 0.8 , goodness-of-fit index (GFI), comparative fit index (CFI), Tucker-Lewis index $(\mathrm{TLI})>0.9$, adjusted GFI (AGFI) $>$ 0.8 , parsimonious normed fit index (PNFI), and parsimonious comparative fit index $(\mathrm{PCFI})>0.5$ [31]. It should be noted that sampling and data collection for EFA and CFA were completed by the first author lasting 5 and 4 months; respectively.

\subsubsection{Reliability}

The reliability of the given scale was calculated by examining Cronbach's alpha coefficient of all the participants ( $\mathrm{n}=$ 203 individuals) after the construct validity was confirmed. The minimum acceptable alpha coefficient was by 0.70 [32]. Moreover, repeatability was investigated through test-retest correlation, completing the scale by 20 ICU patients' family members within a week, and calculating intraclass correlation coefficient (ICC) whose value could be $0-1$, so the closer the value to 1 , the higher the reliability. With reference to $95 \%$ confidence interval, ICC values $<0.50,0.50-0.75,0.75-$ 0.90 , and $>0.90$ represented poor, moderate, good, and high reliability; respectively [33]. 


\section{Results}

\subsection{Phase 1: Item Design}

The main themes following of qualitative study were included: The findings of this study revealed that the families of ICU patients had two basic needs; (1) reducing concerns and (2) being supported. Using conventional content analysis, 5 components (factors) including presence, participation in care and decision-making, dignity and respect, information sharing, and support were extracted from the interviews of participants in the qualitative study section. Based on the searches in articles, 70 articles were initially retrieved. The critical examination was then done at three stages including (a) reading abstracts, (b) examining full texts of the selected articles, and (c) finding suitable statements for the design of FCCSICU items. Studies related to the development and testing of psychometric properties of scales for measuring FCC as well as 26 articles taking account of the concept of FCC, its components (factors) and needs of family members of ICU patients were accordingly selected. About the findings of the qualitative study and the literature review, 68 items were developed. In the structure of the items, articles reflecting on the development and psychometric properties of tools for measuring FCC as well as the needs and satisfaction of ICU patients' family members were mostly employed. After a foursession review by the research team to check the quality of the items and to match them with the findings of the qualitative study and the literature review, the items reduced to 35 cases.

\subsection{Phase 2: Psychometric Properties}

\subsubsection{Face and Content Validity}

In qualitative face validity, ambiguous phrases and words were reviewed. As all the items in the impact factor were $>1.5$, they were preserved. In CVR, 11 items were also removed for being scored $<0.54$. At this stage, according to the panel of experts, the item of "Personnel (physicians, nurses, nursing assistants, etc.) treat us respectfully" were converted into two separate items i.e. "Nurses treat us respectfully" and "Physicians treat us respectfully". The same change was even made in the item of "Nurses and physicians listen to us patiently" into two items of "Nurses listen to us patiently" and "Physicians listen to us patiently". The values of the S-CVI/average and the modified Kappa statistic were also $>0.97$. Therefore, quantitative content validity was approved and the number of FCCS-ICU items reached 26 cases.

\subsubsection{Construct Validity}

Questionnaires returned by four participants were excluded as they had completed all the items with the same responses. The mean age of the participants in EFA and CFA was respectively $40.58 \pm 10.55$ and $38.52 \pm 10.06$ years and no significant difference was observed between the participants in terms of EFA and CFA ( $p$-value $=0.074)$. As presented in Table 1, two groups of the participants did not differ for EFA and CFA about demographic characteristics including gender, marital status, level of education, kinship, diagnosis, and length of stay.

The values of KMO (0.88) and Bartlett's test of sphericity (Chi-square $=1751.031$, p-value $<0.001)$ indicated the ade- quacy of the samples according to the factor analysis. A total of 6 items with commonalities of $<0.5$ were also removed. Items with a high correlation to eigenvalue $>1$ were then placed into one component (factor) and they were assigned a specific name based on the meanings of the items. The results of EFA showed 5 components (factors) in FCCS-ICU including dignity (8 items), receiving information (3 items), support (5 items), family empowerment ( 2 items), and access to a physician ( 2 items) accounting for $20.8 \%, 12.4 \%, 11.6 \%$, $9.6 \%$, and $9 \%$ of the total variance of the FCCS-ICU factorby-factor (Table 2). At this stage, the FCCS-ICU containing 20 items and 5 components (factors) was confirmed.

Table 3 and Fig. 1 illustrate the results of CFA regarding a standard error of measurement for the FCCS-ICU components (factors) including dignity, receiving information, support, family empowerment, and access to the physician. The values of fit indices also show that the model is endowed with goodness of fit and each component (factor) in the FCCS-ICU is approved.

\subsubsection{Reliability}

Cronbach's alpha coefficient of the whole scale was 0.89 . As well, ICC equal to 0.93 ensured its repeatability. The results of Cronbach's alpha coefficient and ICC for each component (factor) are provided in Table 4.

\section{Discussion}

This study aimed to design and test the psychometric properties of a new scale for measuring FCC in ICUs in which, using a multi-stage and comprehensive process, a valid and reliable research tool comprised of 20 items and 5 components (factors) entitled "FCCS-ICU" was developed. The initial items were designed using a qualitative study in which the participants playing roles in FCC implementation including family members of ICU patients and healthcare practitioners in ICUs were included. Conducting a literature review and integrating its results with the findings of the qualitative study along with multiple reviews by the research team, the FCCS-ICU items were developed using a comprehensive look at the study setting and prior research.

The first characteristic of this scale distinguishing it from other tools developed in this field was its design based on a qualitative study. In this respect, studies by Wang et al. (2016) and Mitchell et al. (2012) could be noted; however, items in their scales introduced for measuring FCC in ICUs had not been extracted from a qualitative study, but from existing questionnaires.

The second feature of the FCCS-ICU was that its content validity was confirmed using multiple quantitative and qualitative approaches including face validity and content validity to evaluate clarity, necessity, and relevance of the items, but items in their scales introduced for measuring FCC in ICUs had not been extracted from a qualitative study, but from existing questionnaires [3, 18].

Another characteristic of the FCCS-ICU was an examination of its construct validity using EFA and extraction of 5 components (factors) including dignity, receiving information, support, family empowerment, and access to the physician, 
TA B L E 1. Demographic characteristics of the participant considering EFA and CFA.

\begin{tabular}{lccc} 
Variables & EFA group $(\mathbf{n}=\mathbf{2 0 4}) \mathbf{n}(\mathbf{\%})$ & CFA group $(\mathbf{n}=\mathbf{2 0 3}) \mathbf{n}(\mathbf{\%})$ & p-value* \\
Gender & $70(34)$ & $74(36)$ & 0.58 \\
Male & $136(66)$ & $129(64)$ & \\
Female & & & 0.08 \\
Marital status & $18(9)$ & $26(13)$ & \\
Single & $176(86.5)$ & $170(84)$ & \\
Married & $8(4)$ & $2(20)$ & \\
Divorced & $1(0.5)$ & $17(8.5)$ & \\
Deceased spouse & & $33(16)$ & \\
\hline Level of education & $33(16)$ & $83(41)$ & \\
Primary school & $37(18)$ & $70(34.5)$ & \\
\hline Secondary school & $73(36)$ & & \\
\hline High school & $61(30)$ & & \\
\hline University degree & & & \\
\hline
\end{tabular}

\begin{tabular}{|c|c|c|c|}
\hline \multicolumn{4}{|l|}{ Kinship } \\
\hline Father & $8(4)$ & $7(3)$ & 0.722 \\
\hline Mother & $18(9)$ & $14(7)$ & \\
\hline Spouse & $26(13)$ & $24(12)$ & \\
\hline Son & $45(22)$ & $49(24)$ & \\
\hline Daughter & $74(36)$ & $75(37)$ & \\
\hline Brother & $12(6)$ & $19(9.5)$ & \\
\hline Sister & $21(10)$ & $15(7.5)$ & \\
\hline \multicolumn{4}{|l|}{ Diagnosis } \\
\hline Cardiopulmonary & $54(26.5)$ & $54(27)$ & 0.158 \\
\hline Surgery & $70(34.5)$ & $73(35)$ & \\
\hline Trauma & $46(22.5)$ & $42(21)$ & \\
\hline Internal injuries & $23(11)$ & $24(12)$ & \\
\hline Other & $11(5.5)$ & $10(5)$ & \\
\hline \multicolumn{4}{|l|}{ Length of stay } \\
\hline 5 days & $104(51)$ & $120(59)$ & 0.125 \\
\hline $6-10$ days & $46(22)$ & $44(22)$ & \\
\hline 11 - 15 days & $23(11.5)$ & $18(9)$ & \\
\hline$<15$ days & $31(15.5)$ & $21(10)$ & \\
\hline
\end{tabular}

*Chi-square test $(\chi 2)$

accounting for $63.4 \%$ of the total variance of the scale which was higher than other values in other studies. As in the surveys by Wang et al. (2016) and Mitchell et al. (2012), factors extracted had explained $58.3 \%$ and $43 \%$ of the total variance of the research instruments.

In addition to checking the construct validity via EFA, CFA was also performed using SEM technique, to identify obvious and hidden variables of this new scale and to examine error of measurement as important issues [34]. Fit indices in SEM also confirmed the suitability of the tool and its relationship with other factors and with the total scale. Using this method determining the construct validity of the FCCS-ICU also made it a distinctive tool, as this type of validity had not been investigated in similar studies. [3, 18].

The first component (factor) with the highest percent variance in the FCCS-ICU was dignity including items about treating family members respectfully by healthcare providers, listening to their talks, using simple and intelligible language, giving family members a chance to express their emotions, as well as paying attention to their beliefs and conditions. This component was probably consistent with the one defined as dignity by the institute of patient-family-canted care (IPFCC) as:

"Healthcare practitioners listen to and honor patient and family perspectives and choices. Patient and family knowledge, values, beliefs, and cultural backgrounds are incorpo- 
TA B L E 2. Factors extracted from FCCS-ICU in EFA.

\begin{tabular}{|c|c|c|c|c|c|}
\hline \multirow{2}{*}{$\begin{array}{l}\text { Factors } \\
\begin{array}{r}\text { Factor } 1 \\
\text { (Dignity) }\end{array}\end{array}$} & \multirow{2}{*}{$\begin{array}{l}\text { Items } \\
\text { Personnel (nurses, nursing assistants, etc.) } \\
\text { treat us respectfully. }\end{array}$} & \multicolumn{2}{|c|}{ Factor loading $\mathbf{h}^{2}$ (Communalities) } & \multirow{2}{*}{$\begin{array}{c}\text { Percent } \\
\text { variance } \\
20.8\end{array}$} & \multirow{2}{*}{$\begin{array}{c}\text { Eigenvalue } \\
\qquad 3.95\end{array}$} \\
\hline & & 0.729 & 0.681 & & \\
\hline & Physicians listen to us patiently. & 0.702 & 0.731 & & \\
\hline & Nurses listen to us patiently. & 0.701 & 0.631 & & \\
\hline & Physicians treat us respectfully. & 0.694 & 0.61 & & \\
\hline & $\begin{array}{l}\text { We are given a chance to express our } \\
\text { emotions and concerns. }\end{array}$ & 0.648 & 0.591 & & \\
\hline & $\begin{array}{l}\text { Personnel (physicians, nurses, nursing as- } \\
\text { sistants, etc.) understand our conditions. }\end{array}$ & 0.636 & 0.715 & & \\
\hline & $\begin{array}{l}\text { Nurses and physicians use a simple and } \\
\text { intelligible language as they talk with us. }\end{array}$ & 0.633 & 0.582 & & \\
\hline & $\begin{array}{l}\text { Nurses and physicians consider our beliefs } \\
\text { and views regarding patient care. }\end{array}$ & 0.593 & 0.599 & & \\
\hline \multirow[t]{3}{*}{$\begin{array}{c}\text { Factor } 2 \\
\text { (Receiving } \\
\text { information) }\end{array}$} & $\begin{array}{l}\text { Nurses or physicians give us information } \\
\text { about our patient conditions. }\end{array}$ & 0.747 & 0.688 & 12.4 & 2.86 \\
\hline & $\begin{array}{l}\text { Nurse and physicians answer our questions } \\
\text { if we ask them about our patient. }\end{array}$ & 0.736 & 0.665 & & \\
\hline & $\begin{array}{l}\text { Nurses and physicians give us the same } \\
\text { information about our patient conditions. }\end{array}$ & 0.659 & 0.553 & & \\
\hline \multirow[t]{5}{*}{$\begin{array}{l}\text { Factor } 3 \\
\text { (Support) }\end{array}$} & $\begin{array}{l}\text { If we feel lonely, there is someone to help } \\
\text { forgive it (e.g. a psychologist, a social } \\
\text { worker, a counselor, etc.). }\end{array}$ & 0.715 & 0.569 & 11.6 & 2.38 \\
\hline & $\begin{array}{l}\text { Facilities and accommodations are avail- } \\
\text { able when we are in the hospital. }\end{array}$ & 0.691 & 0.527 & & \\
\hline & $\begin{array}{l}\text { We are allowed to express our opinions } \\
\text { about some care services and treatment } \\
\text { procedures. }\end{array}$ & 0.597 & 0.573 & & \\
\hline & $\begin{array}{l}\text { We receive explanations about side effects } \\
\text { and benefits of each care and treatment } \\
\text { procedure before it is practiced. }\end{array}$ & 0.448 & 0.553 & & \\
\hline & $\begin{array}{l}\text { If there is any problem or complaint, they } \\
\text { are met. }\end{array}$ & 0.437 & 0.559 & & \\
\hline \multirow[t]{2}{*}{$\begin{array}{c}\text { Factor } 4 \\
\text { (Family } \\
\text { empowerment) }\end{array}$} & $\begin{array}{l}\text { We become ready to care for our patient in } \\
\text { other departments or at home. }\end{array}$ & 0.808 & 0.719 & 9.6 & 1.94 \\
\hline & $\begin{array}{l}\text { Nurses or physicians teach us how to take } \\
\text { care of our patient. }\end{array}$ & 0.806 & 0.779 & & \\
\hline \multirow{2}{*}{$\begin{array}{l}\text { Factor } 5 \\
\text { (Access to } \\
\text { physician) }\end{array}$} & It is possible to meet physicians. & 0.784 & 0.669 & 9 & 1.8 \\
\hline & $\begin{array}{l}\text { Physicians give us essential information } \\
\text { about our patient. }\end{array}$ & 0.744 & 0.728 & & \\
\hline
\end{tabular}

rated into the planning and delivery of care." [1]

Similar to confirmation of the FCCS-ICU in the survey by Wang et al. (2016) and the scale introduced by Arslan, Geckil, Aldem, \& Celen (2019), this component had been approved and it was concluded that the given instrument could measure one of the FCC components. [3, 35].
Receiving information from families was the second component in the FCCS-ICU, involving items about receiving responses for questions, getting information about patient health conditions, and gaining the same information from all healthcare providers. This component was also associated with the second element in FCC introduced by IPFCC, that is, 
TA B L E 3. Values of fit indices for the FCCS-ICU in CFA.

\begin{tabular}{lcc} 
Measures & Fit indices & Values \\
P-value $\chi 2$ & $<0.05$ & $<0.001$ \\
CMIN/DF & $<3$ & 1.819 \\
\hline RMSEA & $<0.08$ & 0.064 \\
CFI & $>0.9$ & 0.923 \\
GFI & $>0.9$ & 0.88 \\
AGFI & $>0.8$ & 0.84 \\
TLI & $>0.9$ & 0.91 \\
PNFI & $>0.5$ & 0.682 \\
\hline PCFI & $>0.5$ & 0.743 \\
\hline
\end{tabular}

TA B L E 4. Values of ICC and Cronbach's alpha for the FCCS-ICU.

\begin{tabular}{|lccc|} 
Component (factor) & Cronbach's alpha coefficie & ICC & $\mathbf{9 5 \%}$ CI \\
\hline Dignity & 0.87 & 0.85 & $0.77-0.91$ \\
\hline Recivieng information & 0.71 & 0.78 & $0.73-0.90$ \\
\hline Support & 0.72 & 0.84 & $0.74-0.90$ \\
\hline Empowerment & 0.73 & 0.86 & $0.74-0.92$ \\
\hline Access to physician & 0.7 & 0.75 & $0.53-0.86$ \\
\hline Total & 0.89 & 0.93 & $0.85-0.94$ \\
\hline
\end{tabular}

information sharing. Accordingly, IPFCC had described this component as follows:

"Healthcare practitioners communicate and share complete and unbiased information with patients and families in ways that are affirming and useful. Patients and families receive timely, complete, and accurate information to effectively participate in care and decision-making." [1]

In the survey by Wang et al. (2016), a component named information had been also addressed; while in the study by Arslan et al. (2019), items about sharing information had been incorporated into components (factors) such as support and collaboration. [35]. But, in the study by Shields \& Tanner (2004) and Mitchell et al. (2012), items related to sharing information had been placed into the component called a partnership [16, 18].

The third component in the FCCS-ICU was supported. It was of utmost importance since FCC could fundamentally cover physical, emotional, and spiritual family support and also provide a supportive environment for families. In the questionnaire developed by Shields and Tanner (2004) and Arslan et al. (2019) as well as Measure of Processes of Care [36], all suitable to measure FCC in pediatric settings, support had been also taken into account as one of the components. $[16,35,37]$. Also, in the research instruments developed by Wang et al. (2016) and Mitchell et al. (2012) for measuring the concept of FCC in adult ICUs, support had been raised as one of the factors. Although the meaning of support in the FCCS-ICU might be slightly different from those in other similar tools, support in this scale had reflected on issues such as providing emotional support, offering facilities and accommodations, participating in decision-making, and meeting family complaints, while in the survey by Wang et al. (2016), topics such as listening to family concerns and addressing their needs had been highlighted. The same component in the study by Shields and Tanner (2004) had also shed light on topics such as identifying children's needs, listening to family concerns, and understanding family conditions by personnel. In the scale developed by Arslan et al. (2019), support had been further considered in the domains of support at the time of decision-making, awareness and consultation for decisionmaking, respect for cultural differences, attention to patient privacy, and permission for the presence of family members at the bedside.

Family empowerment was the fourth component in the FCCS-ICU, pointing out educating and preparing family members of ICU patients to provide care at home. In the study by Wang et al. (2016), a component entitled empowerment had been also addressed; however, it included items such as family involvement in decision-making which was not in line with the findings of the present study. In the scale developed by Shields and Tanner (2004), empowerment had been included in another component called collaboration. Moreover, one of the five components in the Measure of Processes of Care was enabling and partnership [37].

The last component in the FCCS-ICU was access to the physician. Perhaps, it could be considered as one of the needs of Iranian families in ICUs. In the study by Bandari et al. (2014) aimed to test the psychometric properties of the Critical Care, Family Needs Inventory, items entitled "Daily talks with physicians" had been considered as information needs of families. [38].

As for access to a doctor, unlike other countries where families and patients participate in different stages of treatment and have the right to make decisions, it seems that in Iran, due 


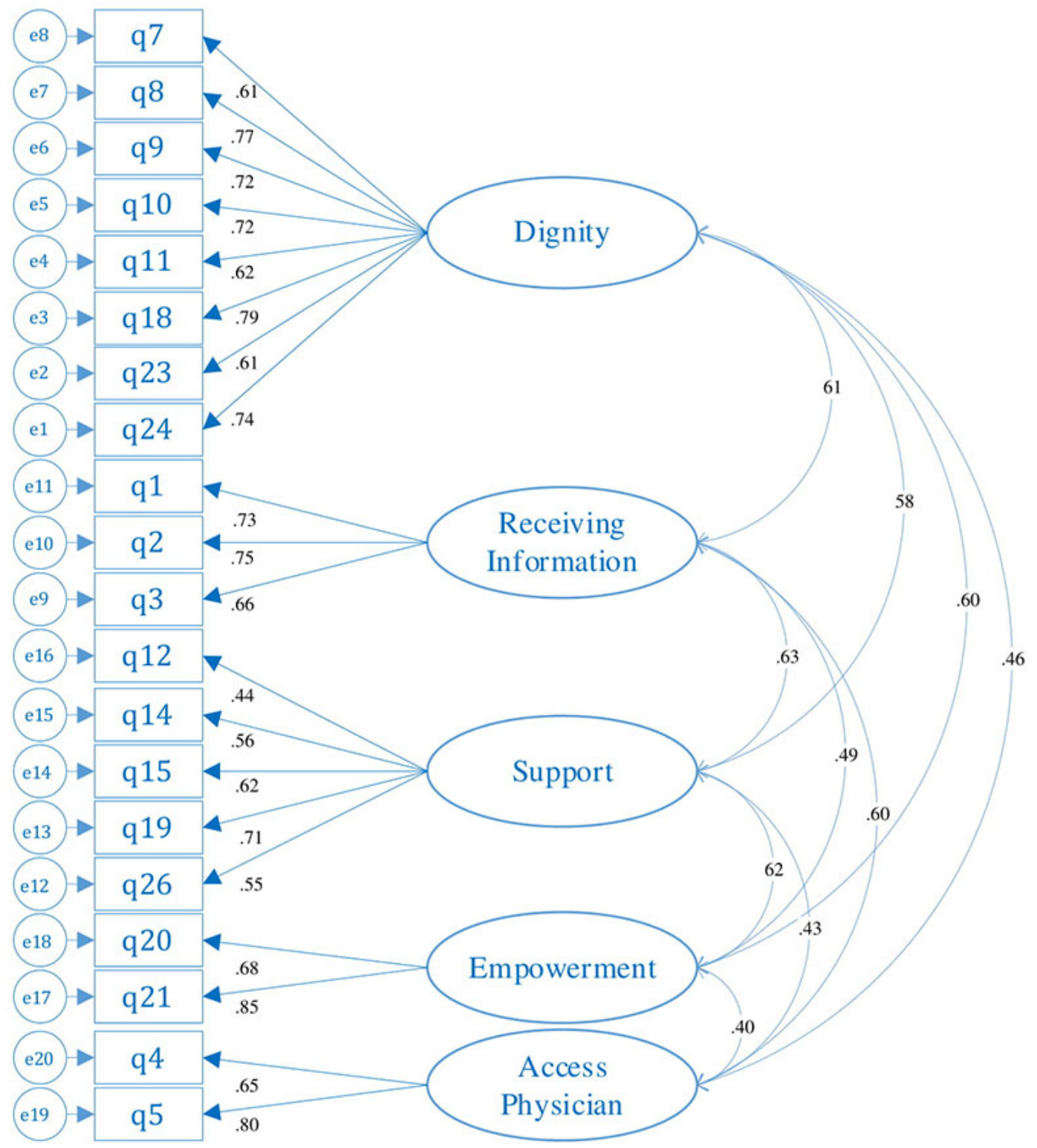

F I G U RE 1. CFA model for the FCCS-ICU using Structural Equation Modeling.

q1: Nurses or physicians give us information about our patient conditions.

q3: Nurses and physicians give us the same information about our patient conditions.

q4: It is possible to meet physicians.

q5: Physicians give us essential information about our patient.

q7: Physicians treat us respectfully.

q8: Personnel (nurses, nursing assistants, etc.) treat us respectfully.

q9: Nurses and physicians consider our beliefs and views regarding patient care.

q10: We are given a chance to express our emotions and concerns.

q11: Nurses and physicians use a simple and intelligible language as they talk with us.

q12: Facilities and accommodations are available when we are in the hospital.

q14: We are allowed to express our opinions about some care services and treatment procedures.

q15: We receive explanations about side effects and benefits of each care and treatment procedure before it is practiced.

q18: Personnel (physicians, nurses, nursing assistants, etc.) understand our conditions.

q19: If there is any problem or complaint, they are met.

q20: We become ready to care for our patient in other departments or at home.

q21: Nurses or physicians teach us how to take care of our patient.

q23: Physicians listen to us patiently.

q24: Nurses listen to us patiently.

q26: If we feel lonely, there is someone to help forgive it (e.g. a psychologist, a social worker, a counselor, etc.). 
to the low level of health literacy, doctors may be the main decision-makers for patients. Also, patients are less involved in selecting possible decisions.

Moreover, Midega, Oliveira, \& Fumis(2019) had noted in their study that having access to physicians and providing clear and complete information in ICUs were among the factors contributing to family satisfaction. [39]. It could be concluded that physicians were in the habit of sharing information about patient conditions with families and nurses were reemphasizing them [40].

According to a review of the related literature, items including the free presence of family members at the bedside and family participation in care and decision-making were incorporated in the initial design of the FCCS-ICU, but they were removed as the psychometric properties of the scale was tested through multiple stages; so they were different from FCC elements in IPFCC and components in scales for measurement of family involvement and collaboration [41].

\section{Conclusion}

The present study aimed to develop and test the psychometric properties of a valid scale for measuring FCC in ICUs, leading to the design of the FCCS-ICU through a qualitative study and a literature review as well as multiple stages of examining psychometric properties. It was concluded that the FCCS-ICU was a reliable research instrument to measure FCC implementation from the perspectives of family members of ICU for the first time in Iran patients considering the components (factors) of dignity, receiving information, support, family empowerment, and access to the physician.

This new scale can be used to determine some of the challenges facing FCC implementation. Thus, nursing managers as the main policymakers in the nursing care of the hospital can use the present scale for assessing the quality of family care of patients in ICU and improving the quality of care in hospitals. Also given that nursing managers and nurses have the most interaction with family members, they can use this tool to better understand the needs and priorities of families and ultimately meet these needs.

Since this scale was developed for the first time in an Asian country with Eastern culture, it is recommended to study and develop it in other nations in terms of cross-cultural adaptation. Due to the critical conditions of patients in ICUs and increasing concerns among families about their health status, data collection from family members was postponed to post-ICUs, so they probably failed to remember all the experiences related to FCC implementation, which is considered as a major limitation of this study.

\section{ACKNOWLEDGMENTS}

We hereby express our gratitude to hospital administrators, all healthcare providers, as well as family members of patients hospitalized in ICUs who participated in interviews.

\section{CONFLICT OF INTEREST}

The authors declared no conflict of interest.

\section{AUTHOR CONTRIBUTIONS}

Vasli Parvaneh: Conceptualization, Methodology, Software, Writing-Reviewing and Editing; Jafarpoor Hasanali.: Data curation, Writing-Original draft preparation; Manoochehri Houman: Visualization, Investigation, Supervision; Zayeri Farid: Software, Formal analysis, Validation.

\section{ETHICAL CONSIDERATIONS}

This study was approved by the institutional review board (IRB) of the Shahid Beheshti University of Medical University with the code no. IR.SBMU.PHARMACY.REC.1397.026. All the participants were also informed about the study objectives and their voluntary involvement. They were further ensured regarding the confidentiality of data and signed informed consent.

\section{FUNDING SOURCE}

This research received no specific grant from any funding.

\section{REFERENCES}

[1] Institute-For-Patient-And Family-Centered-Care. What is patient- and family-centered care. Available: http: //wwwipfccorg.

[2] Wells N, Bronheim S, Zyzanski S, et al. Psychometric Evaluation of a Consumer-Developed Family-Centered Care Assessment Tool Matern Child Health J. 2015;19:1899-1909.

[3] Wang WL, Feng JY, Wang CJ, et al. The Chinese family-centered care survey for adult intensive care unit: A psychometric study. Appl Nurs Res. 2016; 29:125-130.

[4] Westbrook K, Grant C, Rafalski E, et al. Patient-family Centred Care: Measuring Perceived Service Quality Following a Critical Care Services Experience. Journal of Health Management. 2015;17:304-315.

[5] Marshall J, Bosco L, Adhikari N, et al. What is an intensive care unit? A report of the task force of the World Federation of Societies of Intensive and Critical Care Medicine. Journal of Critical Care. 2017;37:270-276.

[6] Brown S, Rozenblum R, Aboumatar H, et al. Defining Patient and Family Engagement in the Intensive Care Unit. American Journal of Respiratory and Critical Care Medicine. 2015;191:358-360.

[7] Herbst L, Desai S, Benscoter D, et al. Going back to the wardtransitioning care back to the ward team. Transl Pediatr. 2018;7:314-325.

[8] Owens R, Huynh T, Netzer G. Sleep in the Intensive Care Unit in a Model of Family-Centered Care. AACN Adv Crit Care. 2017;28:171-178.

[9] Brown S, Aboumatar H, Francis L, et al. Balancing digital informationsharing and patient privacy when engaging families in the intensive care unit. J Am Med Inform Assoc. 2016;23:995-1000.

[10] Hwang D, El-Kareh R, Davidson JE. Implementing Intensive Care Unit Family-Centered Care: Resources to Identify and Address Gaps. AACN Advanced Critical Care. 2017;28:148-154.

[11] Al-Motlaq MA, Abuidhail J, Salameh T, et al. Development and validation of an instrument to assess the implementation of family-centred care in traditional open bay Neonatal Intensive Care Units. Early Child Development and Care. 2017;187:168-177.

[12] Asai H. Predictors of nurses' family-centered care practises in the neonatal intensive care unit. Japan Journal of Nursing Science.2011;8;5765.

[13] Al-Motlaq MA. Traditional open bay neonatal intensive care units can 
be redesigned to better suit family centered care application. Journal of Neonatal Nursing. 2018;24:159-162.

[14] Segers E, Ockhuijsen H, Baarendse P, et al. The impact of family centred care interventions in a neonatal or paediatric intensive care unit on parents' satisfaction and length of stay: a systematic review. Intensive and Critical Care Nursing. 2019;50:63-70.

[15] Al-Motlaq MA, Shields L. Family-Centered Care As a Western-Centric Model in Developing Countries. Holistic nursing practice. 2017;31:343347.

[16] Shields L, Tanner A. Pilot study of a tool to investigate perceptions of familycentered care in different care settings. Pediatric Nursing. 2004;30:189-197.

[17] Curley M, Hunsberger M, Harris S. Psychometric Evaluation of the Family-Centered Care Scale for Pediatric Acute Care Nursing. Nursing Research.2013;62:160-168.

[18] Mitchell M, Burmeister E, Chaboyer W, et al. Psychometrics of the "Family-Centred Care Survey - Adult Scale". The International Journal of Person Centered Medicine. 2012;2:792-798.

[19] Himuro N, Kozuka N, Mori M. Measurement of family-centred care: translation, adaptation and validation of the Measure of Processes of Care (MPOC-56 and -20) for use in Japan. Child Care Health Dev. 2013;39:358-365

[20] Feeg V, Paraszczuk A, Çavuşoğlu H, et al. How is Family Centered Care Perceived by Healthcare Providers from Different Countries? An International Comparison Study. J Pediatr Nurs. 2016;31:261-276.

[21] Alabdulaziz H, Moss C, Copnell B. Paediatric nurses' perceptions and practices of family-centred care in Saudi hospitals: A mixed methods study. Int J Nurs Stud. 2017;69:66-77.

[22] Kazer M, Fitzpatrick J. Encyclopedia of nursing research. Springer Pub, 2012.

[23] Polit DF, Yang F. Measurement and the Measurement of Change: A Primer for the Health Professions. Wolters Kluwer, 2016.

[24] Polit D, Beck C. Nursing research : generating and assessing evidence for nursing practice. Philadelphia Wolters Kluwer Health, 2017.

[25] Miller L, McIntire S, Lovler R. Foundations of psychological testing: A practical problem. Sage Publications, 2011.

[26] Polit D, Beck C. Essentials of Nursing Research: Appraising Evidence for Nursing Practice. Lippincott Williams \& Wilkins, 2009.

[27] Polit D, Beck C, Owen S. Is the CVI an Acceptable Indicator of Content Validity? Appraisal and Recommendations. Research in Nursing \& Health. 2007;30:459-647.

[28] Waltz C, Strickland O, Lenz L. Measurement in Nursing and Health Research. Springer Co. 2010.
[29] Munro B, Plichta S, Kelvin E. Statistical methods for health care research. Lippincott Williams \& Wilkins. 2005.

[30] Hair J, Black W, Babin B, et al. Multivariate data analysis. England and Associated Companies throughout the world, Upper Saddle River, NJ. 2009.

[31] Hooper D, Coughlan J, Mullen M. Structural Equation Modelling: Guidelines for Determining Model Fit. Electronic Journal of Business Research Methods. 2008;6:53-60.

[32] Burns N, Groves SK. The Practice of Nursing Research: Appraisal, Synthesis, and Generation of Evidence. Elsevier Health Sciences, 2012.

[33] Koo T, Li M. A Guideline of Selecting and Reporting Intraclass Correlation Coefficients for Reliability Research. J Chiropr Med. 2016;15;155-163.

[34] Lomax R, Schumacker R. A beginner's guide to structural equation modeling. psychology press. 2004.

[35] Arslan F, Geckil E, Aldem M, et al. The family-centered care assessment scale: Development and psychometric evaluation in a Turkish sample. J Pediatr Nurs. 2019;48:e35-e41.

[36] Graneheim U, Lundman B. Qualitative Content Analysis In Nursing Research: Concepts, Procedures And Measures To Achieve Trustworthiness. Nurse Education Today. 2004;24:105-112.

[37] Cunningham B, Rosenbaum P. Measure of processes of care: a review of 20 years of research. Dev Med Child Neurol. 2014;56:445-452.

[38] Bandari R, Heravi-Karimooi M, Rejeh N, et al. Psychometric properties of the Persian version of the Critical Care Family Needs Inventory. J Nurs Res. 2014;22:259-267.

[39] Midega T, Oliveira H, Fumis R. Satisfaction of family members of critically ill patients admitted to a public hospital intensive care unit and correlated factors. Rev Bras Ter Intensiva. 2019;31:147-155.

[40] Hashim F, Hussin R. Family Needs of Patient Admitted to Intensive Care Unit in a Public Hospital. Procedia -Social and Behavioral Sciences. 2012;36:103-111.

[41] Ebrahimi H, Sadeghian E, Seyedfatemi N, et al. Contextual factors affecting autonomy for patients in Iranian hospitals: A qualitative study. Iran J Nurs Midwifery Res. 2016;21:261-270.

How to cite this article:Hasanali Jafarpoor, Parvaneh Vasli, Houman Manoochehri, Farid Zayeri. Measuring Family-centered Care in Intensive Care Units: Developing and Testing Psychometric Properties. Signa Vitae. 2020;16(2):82-91. doi:10.22514/sv.2020.16.0047. 